\title{
Establishment of a world food preservation center
}

\author{
Charles $L$ Wilson
}

\begin{abstract}
A World Food Preservation Center (WFPC) is proposed in response to a pending civilization-threatening food shortage and our limited ability to adequately increase food production. Some estimates put losses of food in developing countries after it is produced and before it is consumed at 50\%. These losses are particularly threatening to individuals and farmers who are living in the midst of food insecurity. Although numerous organizations have attempted to address this problem worldwide, the magnitude of the effort has not come close to the enormity of the problem. Most of these programs are also short-term and require continuous input by postharvest specialists from developed countries in order to be sustainable. A critical need exists for a substantial and sustainable worldwide program that can significantly reduce losses and waste of food in developing countries. The World Food Preservation Center proposed here meets this need by educating young scientists in developing countries about low-input, appropriate technologies for preserving food postharvest. It also conducts research on postharvest technologies especially suited for application in developing countries such as biological control, solar refrigeration, and coordinated transport and marketing schemes that support and sustain the local production of food commodities.
\end{abstract}

Keywords: Food insecurity, Postharvest losses, Developing countries, Postharvest food preservation

\section{Background}

World food supply and demand on a collision course Our food supply is profoundly affected worldwide by climate conditions, soil fertility, and the availability of water, arable land, and low-cost energy. The world struggles to produce food in the face of rising populations, limited energy supplies, and the degradation of our soil and fresh water. World grain production has fallen short of grain consumption in 7 of the past 12 years, and reserves remain critically low [1].

According to Pemitel and Giampietro [2] nearly onethird of the World's cropland (115 billion hectares) has been abandoned due to soil erosion and loss of fertility. Dwindling water supplies pose a major threat to food production since $70 \%$ of all water use is for agriculture. According to Spiegel Online International [1],

'Of all the environmental trends that are reducing the world's food supplies, the most immediate is water shortages. In a world where 70 percent of all available

Correspondence: charliewilson@citlink.net

Wilson Associates International LLC, Box 1194, Shepherdstown, WV 25443, USA

\section{Biomed Central}

fresh water use is for irrigation, this is no small matter. The drilling of millions of irrigation wells has pushed water withdrawal in many countries beyond recharge rates from rainfall, leading to groundwater mining. As a result, water tables are now falling in countries that contain half the world's people, including the big three grain producers - China, India, and the United States'.

Climate change is resulting in erratic and severe weather patterns that are profoundly affecting food production worldwide. Agricultural regions around the world are experiencing more intense heat waves, as well as monsoon-like rains and devastating floods. Since crops were developed to produce maximum yields under optimal growing conditions, environmental stresses resulting from climate change are causing dramatic reductions in crop yield or complete crop failures.

Sustaining and increasing crop yields represents a major challenge to agricultural scientists and plant breeders. While science and technology have historically greatly increased food availability, we are definitely facing a potential food production crisis brought about by climate change and the unprecedented number of 
people that now populate and will populate the earth in future years. We are approaching the upper limits of the earth's human carrying capacity. It is questionable whether advances in crop production can address these problems in a timely manner and keep up with food demand. A civilization-threatening food shortage is a real possibility. Clearly, a comprehensive plan is needed to tackle this impending disaster and is needed now.

\section{What if we cannot produce our way out of this crisis?}

In the past, man has been able to increase food production through breeding and genetic selection. Although this has been a highly successful approach, increasing maximum yields of many crops has required the addition of more and more external inputs. Breeding plants to produce sustained, high yields under suboptimal growing conditions will require a tremendous input of resources and take many years, as it has not been a high priority in most breeding programs.

More recently, crop geneticists have been breeding crop plants using the tools of molecular biology to produce genetically modified organisms (GMOs). This approach, however, has been met with a great level of cultural and political resistance due to health and environmental concerns. Additionally, whether one can increase stress tolerance to a degree that addresses the problems associated with climate change and the loss of high quality arable land, while still maintaining high yields, is an open question. Unfortunately, the major thrust in this area has been to increase yields by making the crop more resistant to herbicides. This questionable approach increases yield through weed control by the increased use of herbicides resulting in greater contamination of the environment with synthetic herbicides. More recent applications utilizing GMOs to enhance drought tolerance and yields will be more sustainable.

The question becomes what other approaches can we take that would address the major food shortages that are bearing down on us, preferably approaches that are sustainable and environmentally friendly. The need to increase the food supply in developing countries is particularly critical since many individuals in these countries live under a constant threat of crop failure and famine.

\section{Increasing our food supply by reducing postharvest losses and waste}

Postharvest losses of food arguably pose our greatest vulnerability to food security worldwide. Estimates of postharvest losses of food are highly variable. In developed countries postharvest losses and waste of food have been estimated to be from 10 to $60 \%$. In developing countries these losses often run at $50 \%$ or more. A United Nations Food and Agriculture Organization (FAO) study estimates that one-third of the food produced for human consumption is lost worldwide after harvest [3].

All estimates of postharvest losses are probably conservative in that they do not reflect the cumulative losses from all stages in the food pipeline from the field to the fork. Although there is no agreement on the specific percentages of postharvest losses, there is no doubt that these losses are enormous and merit worldwide attention. Unfortunately, most of the resources directed toward our postharvest problem have been used to study the problem rather than attack it. This is not to negate a number of highly effective programs that have addressed this problem in academia, the United Nations FAO, and international laboratories. Kader [4] has recently written a very comprehensive review on postharvest educational and extension efforts internationally and pointed out opportunities for collaboration. The Postharvest Education Foundation is doing an excellent job of developing and implementing postharvest extension programs for farmers in developing countries [5].

\section{The magnitude of the effort needs to match the enormity of the problem}

Although considerable attention has been drawn to the enormity of food losses and waste due to postharvest spoilage [3], a limited number of resources have been devoted to its solution. Although there are excellent extension and educational programs that address postharvest losses encountered in developing countries, this total effort does not approach the enormity of the problem. Also, present programs in many cases are not sustainable since they are dependent on a continual input from postharvest specialists in developed countries with irregular and uncertain budgets.

\section{Establishment of a world food preservation center}

I propose an initiative that can have a major impact on reducing postharvest losses in developing countries worldwide and that will not require a continuous input from postharvest specialists in developed countries. It involves the establishment of a World Food Preservation Center that would educate young scientists in developing countries in adaptable appropriate technologies for food preservation, and conduct postharvest research that is especially suited to sustain and support food production in these countries. This concept has been received enthusiastically by young scientists in developing countries who are motivated to solve their own problems [6].

The World Food Preservation Center will educate native scientists from developing countries and arm them with the latest technologies for food preservation in their country. Such individuals would be able to return to their country and develop self-sustaining educational and extension programs on their own. These programs 
will continue to grow through the education received by students of these native scientists. Farmers in these countries will be educated through extension programs demonstrating the latest technologies adapted for their postharvest preservation needs. Given that many farmers in developing countries live on the margins of food insecurity, a reduction in postharvest losses could have an immediate and significant impact on their livelihoods. Once the seeds of the World Food Preservation Center are sown it is expected that they will grow to have a major positive impact on the food security of participating developing countries.

\section{Research arm of the world food preservation center}

Notable research programs worldwide have developed technologies that are well suited for food preservation in developing countries. However, there has not been a comprehensive research program directed solely toward developing a broad spectrum of postharvest technologies to meet the specific needs of developing countries. Development of a cold chain, powered by solar energy, for food from harvest to the consumer in developing countries will be a major research objective of the World Food Preservation Center. A number of other exciting possibilities exist, such as solar powered tractors and food transporters. Since many developing countries have a surplus of solar energy and a shortage of fossil-based fuels the capturing of solar energy for the cultivation, preservation, and transport of food seems like a natural that deserves consideration.

Both high- and low-tech solutions for food preservation will be the subject of research at the World Food Preservation Center. Students attending the Center will bring a contemporary picture of the postharvest problems that exist in their countries and the adaptability of present technologies. They will also be able to bring knowledge of current postharvest technologies that are being used effectively in their countries.

The World Food Preservation Center will pursue biologically-based technologies for the preservation of food including the use of natural antagonists and natural biocidal compounds for the control of postharvest decay. These biopesticides will help reduce postharvest losses in a sustainable way without contaminating food and the environment with synthetic pesticides.

\section{Uniqueness of the world food preservation center}

The proposed World Food Preservation Center is unique among existing programs that are addressing postharvest losses in developing countries, in that its research will be focused solely on the postharvest problems of developing countries. Scientists educated at the World Food Preservation Center will be able to return to their native countries and establish self-sustaining independent research and extension programs on postharvest technologies suited for their countries. These scientists can form satellites of the World Food Preservation Center resulting in a worldwide network that can advance the application of the most advanced technologies for the preservation of food, as well as conduct research that is targeted toward technologies needed specifically by developing countries. The World Food Preservation Center can serve as a communications hub worldwide for postharvest scientists in developed and developing countries.

\section{A virtual world food preservation center}

A group of scientists have joined me to build interest in this concept (see Acknowledgements). We are in the process of building a website that can serve as a virtual World Food Preservation Center and a means of advancing this concept until the physical World Food Preservation Center is established. Among the many features planned for the Virtual World Food Preservation Center are: (1) a virtual library of resources for the postharvest preservation of food; (2) a distance-learning center that will provide the undergraduate education needed for those wanting to receive advanced degrees from the World Food Preservation Center; (3) a comprehensive listing of present programs on the postharvest preservation of food in developing countries; (4) a listing of equipment manufacturers with postharvest technology for developing countries, and (5) an 'Ask an Expert' portal for information exchange.

\section{The economics of investing in technologies to reduce postharvest losses in developing countries}

Economic arguments for investing in the development of postharvest research and extension programs in developing countries are compelling. There would be a tremendous return on investment. A study in India determined that at least $50 \%$ of the production of fruits and vegetables is lost due to wastage and value destruction [7]. The cost of wastage was estimated at US $\$ 4.6$ billion per year. Investment in a program that would reduce these losses by only $5 \%$ would result in a return of $\$ 2.3 \mathrm{M}$ dollars per year. This is one commodity in one country. Imagine the economic impact of developing and implementing technologies that could reduce postharvest losses worldwide by $5 \%$, not to mention the attendant impact on reducing world hunger, improving world health, and reducing negative impacts on the environment. Unlike the annual investment required in crop production, a one-time investment in postharvest technology such as a storage facility can yield multiple years' returns. 


\section{Who needs to invest in the world food preservation center?}

It has been estimated that $95 \%$ of our research dollars are directed toward the production of food with a disproportionate $5 \%$ toward food preservation [8]. With the obvious return on investment in technologies to reduce postharvest losses in developed and developing countries, why are we not investing more in initiatives like the World Food Preservation Center? Agri-business has not invested extensively in postharvest technologies for developing countries because of a perceived low return on investment, except in the development and marketing of postharvest synthetic pesticides. A new business model is emerging that might help in the support and implementation of postharvest technologies for developing countries. This is exemplified by GrainPro, Inc. \{Concord, MA, USA.\} that has established a not-just-forprofit company that sells and distributes advanced technologies for grain storage such as bags that extend the freshness of grains and coffee [9]. Such companies could partner with the World Food Preservation Center in conducting research and transferring its innovative technology.

Who would receive the greatest returns on investments in postharvest technologies for developing countries? Among the greatest benefactors will be citizens and farmers in developing countries along with the world at large through increasing our food supply, reducing world hunger, and enhancing the health of the world's citizens. These are all humanitarian goals that are being pursued by philanthropic granting agencies and some private and governmental agencies. Perhaps seed monies provided by granting agencies and private and governmental agencies could be matched by a host educational institution. We need to convince all potential investors of the need to establish a World Food Preservation Center if we are to responsibly face pending food shortages that are bearing down on all of us.

\section{A partner not a competitor}

The World Food Preservation Center plans to partner with existing programs that are addressing the need for effective technologies to reduce postharvest losses in developing countries. Because of its singular focus it is hoped that it will augment and amplify present programs addressing these problems. We hope with this article to find partners and build a cooperative effort to effectively address perhaps one of the most critical problems of our time.

\section{Conclusion}

There is agreement worldwide that postharvest food losses and waste in developing countries are an enormous problem. The World Food Preservation Center proposed here has the potential of having a major impact in solving this problem in a sustainable manner with a positive impact on world hunger and health.

\section{Competing interests}

The author declares that he has no competing interests.

\section{Acknowledgements}

I have had the good fortune to have been joined in this effort by a group of leaders in the field whose counsel and ideas are reflected in this article. My heartfelt appreciation is given to them for their help and encouragement: Adel Kader, Professor Emeritus, University of California; Lisa Kitinoja, Founder, Postharvest Education Foundation; Ken S Marsh, President, Kenneth S Marsh Associates, Ltd.; Gage Williams, Chairman, West County Renewables Ltd, UK; Tatiana Koutchma, Leader of Food Preservation Group, Guelph Food Research Center, Canada; Charles W. Wilson, Writer and Journalist, New York Times; and Michael Wisniewski, Lead Scientist, USDA ARS.

Received: 7 August 2012 Accepted: 16 October 2012

Published: 1 January 2013

\section{References}

1. Spiegel International: The Geophysics of Food Scarcity. 2009. http://www. spiegelde/international/world/worldwide-crisis-the-geopolitics-of-foodscaricity-a-606937.htm webcite.

2. Pimentel D, Giampietro: Food, Land, and the U.S. Economy. San Francisco, CA 94104-0457: Carrying Capacity Network; 1994.

3. Gastavsson J, Cederberg C, Sonesson U: Global Food Losses and Food Waste. Rome: Food and Agriculture Organization (FAO) of the United Nations; 2011.

4. Kader AA: Opportunities for international collaboration in postharvest education and extension activities. Act Horticulturae. ISSN 0567-7572] 2012 (in press).

5. Postharvest Education Foundation. http://postharvest.org/homeO.aspx webcite.

6. Wilson CL: Linkedln Discussion "How about a WORLD FOOD PRESERVATION CENTER that would train young scientists in developing countries in advanced postharvest technologies and develop new technologies such as solar refrigeration?". 2012, http://www.linkedin.com/groupAnswers? viewQuestionAndAnswers=\&discussion ID=110145279\&gid= 3770124\&commentID=80429933\&trk=view_disc\&ut=36TxbG6mlC15g1 webcite.

7. Rolle RS: Postharvest Management of Fruit and Vegetables in the Asia-Pacific Region. E-books on Agriculture. APO Asian Production Organization; 2006. http://www.apo-tokyo.org/ooe-books/AG-18_PostHarvest.htm webcite.

8. Kader AA, Rolle RS: The Role of Post-harvest Management in Assuring the Quality and Safety Horticultural Crops. 152nd edition. FAO Agricultural Services Bulletin; 52.

9. GrainPro, Inc. http://www.grainpro.com webcite.

doi:10.1186/2048-7010-2-1

Cite this article as: Wilson: Establishment of a world food preservation center. Agriculture \& Food Security 2013 2:1.

\section{Submit your next manuscript to BioMed Central and take full advantage of:}

- Convenient online submission

- Thorough peer review

- No space constraints or color figure charges

- Immediate publication on acceptance

- Inclusion in PubMed, CAS, Scopus and Google Scholar

- Research which is freely available for redistribution 